\title{
Learning e-Learning Skills for Vocational Training Using e-Learning: The Experience Pilonting the (e)VET2EDU Project Course
}

\author{
Isabel Gutiérrez, M. Mar Sánchez, Linda Castañeda, and Paz Prendes
}

\begin{abstract}
In this paper we present principal data of the experience of the piloting of a European eLearning international course VETeL. The Project E-VET2EDU "Supporting vocational teachers and trainers in eLearning" is a two-year international project, funded by the European Union, that has developed and piloted a completely open online course (VETeL), in 9 different languages, aimed to train vocational trainers in the facilitation of eLearning courses.

Taking into account that the main gal of this project is not only the development of the course's materials and the multilingual learning environment related to the course, but the improvement of the knowledge about VET, the experience of students, facilitators and coordinators of the course it is very important. It could be crucial for the improvement of the course itself, as well as for getting a better knowledge about how the participants of an online course in a non-traditional modality of formal learning are affected by the different aspects of this and give us some key points for improving
\end{abstract}

Index Terms-Vocational educational training, elearning, course, piloting, open online course, OOC.

\section{INTRODUCTION}

The transformations occurring in Vocational Educational Training (VET) system are a common denominator of almost all the educational systems within EU. The project E-VET2EDU [1]. Supporting vocational teachers and trainers in eLearning (available: http://evet2edu.eu/index.html) provided an eLearning course for vocational schools and training sector. The e-course called VETeL, is an completely free open online course, which resources are translated into 9 different languages (Polish -PL-, Croat -CR-, Slovenian -SL-, Lithuanian -LT-, Italian -IT-, Spanish -ES-, Norwegian -NO-, Czech - CZ- and English -EN-), and provided with a detailed Facilitator's Handbook, aiming at:

- Supporting trainers and teachers from VET sector in the implementation of dynamic, open and innovative methods.

- Increasing didactic and digital competences of VET trainers and teachers.

- Raising awareness about online educational solutions based on innovative pedagogy.

- Increasing the visibility and role of VET in regular education system and lifelong learning.

Manuscript received July 20, 2015; revised January 20, 2016. This work was totally supported by the European Commission under the Lifelong Learning Programme.

The authors are with the Department of Didactics and School Organization, University of Murcia, Spain (e-mail: isabelgp@um.es, mmarsanchez@um.es, lindacq@um.es,pazprend@um.es).
The aim of the piloting process is to improve this e-course and the facilitator's Handbook, so as to ensure a high quality of the final product, and at the same time, give us some relevant information in order to improve the knowledge we have about a very important part of our educational systems -vocational educational training- that is more and more crucial in a knowledge society that try to learn all across its life.

\section{VocAtional EdUCATIONAL TRAINING IN EUROPE}

These are challenging times for VET. In one hand, Information and Communication Technologies (ICT) have created new demands for education in general and VET in particular, with regards to the new social and productive requirements. On the other, the quality, efficiency, openness and equal access of the training need to take advantage of ICT.

It is necessary to train using ICT, for and ICT society and trough ICT, within more flexible educational frameworks and environments that create the new conditions for a continuous learning.

In a European clear bet for VET, it's essential to strengthen the necessary conditions to adapt the skills and qualifications of the people to the requirements and demands of the current production environment (affected by the global crisis, the increase of the emerging economical powers, unemployment, demographic change and inequality, climate change and also the increasing and fast technological change).

In order to find out the start of the politics and the essential educational changes that give room to the information and knowledge society in the field of vocational education and training systems, and with the point of view of a reinforced cooperation at an European level, we need to place ourselves in the Process of Copenhagen (in the Lisbon 2000 framework) and its outcomes about an action plan for 2002-2010 [2].

Its continuity nowadays, and after several communications that have developed it during the years 2004, 2006 and 2008, it's established through the Bruges Communication, with a new strategy for the period 2011-2020. This strategy gives an answer to the revision of the Copenhagen achievements until the year 2011. Therefore, in order to "improve the quality and efficiency of VET, and to enhance its attractiveness and relevance, VET should have high relevance for the labor market and people's careers" [3]. Regarding this goals the European Union (EU) Members try to carry on initiatives directed to get the following strategic objectives:

1) Making Initial VET (I-VET) an attractive learning option. 
2) Fostering the excellence, quality of teachers, trainers and other VET professionals, as well as to enhance the VET labour market relevance.

3) Enabling flexible access to training and qualifications regarding I-VET and Continuing VET (C-VET).

4) Developing a strategic approach to the internationalisation of I-VET and C-VET and promoting international mobility.

5) Fostering innovation, creativity and entrepreneurship, as well as the use of ICT (in both I-VET and C-VET).

6) Promoting equity, social cohesion and active citizenship, realising inclusive I-VET and C-VET

7) Increasing the involvement of VET stakeholders and visibility for the achievements of European cooperation in VET.

8) Coordinate the governance of European and national instruments in the areas of transparency, recognition, quality assurance and mobility

9) Intensifying cooperation between VET policy and other relevant policy areas

10) Improving the quality and comparability of data for EU policymaking in VET

11) Making good use of EU support

After a look to the previous list we can find how the study, as well as the proposal of the project, acquire full meaning in order to improve the system in the way of a more modern VET, able to respond to the labour challenges, and that need to be adapted to the new open and globalized market created by ICT.

\section{A. The Importance of e-Learning in VET Contexts}

The labour market and the demanding jobs are absolutely linked to an essential improvement of the educational level. It's necessary to train future workers in a way that enables their integration in a modern production apparatus conditioned by the technological progress. Therefore, the necessary human resources, the workers of the knowledge society, need to have higher technological training; so investing in ICT is a must. That's it, to take advantage of the ICT possibilities in the area of VET by using new flexible environments in training and from the perspective of lifelong learning. And this is a clear compromise and objective to be reached in 2020, according to the legislation mentioned.

The virtual learning environments, the eLearning, can be defined as "The use of technologies in learning opportunities, encompassing flexible learning as well as distance learning; and the use of information and communication technologies as a communication and delivery tool between individuals and groups, to support students and improve the management of learning", according to the Higher Education Funding Council for England [4].

Therefore, eLearning shows itself as a clear alternative with a great potentiality in reply to the recommendations from the general legislative framework in VET, as well as by UNESCO2. As early as 2002 UNESCO [5]. issued a report about the current and future advantages of open distance learning.

In particular, an regarding VET, the agued references throughout this work make a clear bet for enhancing creativity, innovation and entrepreneurship as well as the use of ICT; which should be used to maximise the access to training and to promote active learning, as well as to develop new methods in both work and school-based VET.

The initiative "eLearning: designing tomorrow's education", launched in May 2000 by the Commission, in response to the Lisbon Council, was endorsed by the European Council at its meeting in Feira in June 2000 [6]. At its meeting in Stockholm in March 2001, the European Council noted the positive results of the initiative. The "eLearning Action Plan" developed the four action lines of the eLearning initiative (infrastructures and equipment, training, European quality contents and services and cooperation at all levels) in 10 key actions, bringing together the various Community programmes and instruments, for an increased coherence and synergy between them and for enhanced accessibility to users.

However, and in spite of the flexible learning integration being already a compulsory requirement for the formal institutions in the UE, [4] points out in the afore mentioned report the lack of teacher training, administrative system and support tutorials for students, quality design of courses, methodology used and evaluation designs [7], [8]. Therefore, and although there are some timid initiatives in VET, a lot is still to be done.

Summing up, it's necessary a definitive unfolding of the elearning in VET as a proven plan of improvement in the worker's training and their integration in the labour market [9], as well as for the increase in the technological qualification of the citizens and the increase in the general knowledge [10]. ELearning allows a more flexible training that adapts to difference profiles with greater number of users and under the same premises of shared knowledge building in cooperation [9], [10]. Therefore, the required competence standards required in VET have to be acquired trough flexible training environments among others; being eLearning the one chosen.

\section{VETEL E-COURSE AND HANDBOOK}

The main goal of the VETeL e-course is to develop in the participants, the competence to plan an eLearning course for a VET context using exercises and elements of the online teaching strategy and exploiting a variety of tools and teaching methods specifically selected to meet their goals.

VETeL e-course is a task-based-learning online course, based on a Social Constructivism approach that try to stimulates self-directed learning skills and is configured by 10 modules that covered about 60 hours of learning:

- Module 1:Introduction \& Warm-up

- Module 2:Developing competences

- Module 3:Exploring eLearning

- Module 4:Designing e-tivities

- Module 5:Developing eLearning resources

- Module 6:Online resources - reusing, sharing and evaluating

- Module 7:Motivation

- Module 8:Group work

- Module 9:Moderating online forum discussion

- Module 10:The role of the facilitator Final Stage 
Participants are encouraged to interact within the group and to create meaningful and relevant works and reflections. Consequently, each module is organised in short and interactive tasks, some of them, for being developed in peer groups where communication is crucial.

Therefore, the working space for the pilot version of the e-course was based on MOODLE (http://evet2edu.eu/moodle1), it has observe all the accessibility standards and it has included the use of some external Web 2.0 tools (open and/or free), such as collaborative whiteboards, videoconferences, group editing and co-working spaces.

In addition to the course materials and organization, it has been developed a "Facilitator's Handbook", that is a detailed course guide composed of 10 modules, which aimed at helping the facilitator during the implementation of the e-course.

The entire course -including the facilitator handbook- is open and public, licensed under Creative Commons Attribution 3.0 and, as we said previously, it was developed in 9 languages (PL, CR, SL, LT, IT, ES, NO, CZ, EN) and piloted in 8 countries (Poland -PL-, Croatia -CR-, Slovenia -SL-, Lithuania -LT-, Italy -IT-, Spain -ES-, Norway -NO-, and Czech Republic-CZ-).

\section{The PILOTING}

\section{A. Piloting Procedure}

The e-course was translated into 8 partners' languages, and all its contents were uploaded on Moodle platform. Afterwards, each partner was responsible for the localization of each country version of the course.

The main target group of the project where VET teachers and trainers, therefore the course was tested directly on MOODLE by them.

There were 3 principal participant roles involved in each version of the piloting phase: the local coordinator, who was responsible for the fulfilment of the overall piloting activity; the facilitator, who was responsible for the course de livery and for learners' support; the course participants/learners, who tested and evaluated the e- course by answering questionnaires.

The Piloting activity started with the recruitment of the facilitators, who have moderated the e-course during the piloting phase, supporting the course participants. After the recruitment of the facilitators the promotional phase in each country started which aimed at involving learners in the pilot of the course, it included newsletters, website articles, social media posts. Finally, after having completed the national registration form (CS ES HR IT LT NO SL PL), the learners (VET teachers and trainers) were enrolled in the course.

The piloting lasted about 3 months.

\section{B. Piloting Tools}

The piloting process was structured in the same way for all the partners, by using the equivalent evaluation questionnaires. Besides the common evaluation outline, a reasonable degree of flexibility was guaranteed to partners so that they could define the process in detail to respond to their specific national context and language code.

In order to conduct a well structured Piloting activity a Piloting Handbook with the following annexes was delivered to the partners: the Learner's Questionnaire form (Annex A) to gather the learner's feedback; the Facilitator's Questionnaire form (Annex B) to collect the facilitator's feedback. In addition to the Evaluation questionnaires listed above, questions for people who decided to leave the course and criteria for the external evaluation were defined. Consequently, it also contributed to the improvement of the (e)VET2EDU final eLearning course.

\section{Learner's Course Evaluation}

There were four evaluation questionnaires for the learners, they had the opportunity to evaluate a range of items by ticking one of 4 possible answers: definitely yes; rather yes; rather not; definitely Not. The number of participants is detailed in the following table in Fig. 1:

\begin{tabular}{|l|l|l|l|}
\hline & $\begin{array}{l}\text { Number of } \\
\text { participants who } \\
\text { started the e- } \\
\text { course }\end{array}$ & $\begin{array}{l}\text { Number of } \\
\text { participants who } \\
\text { continued the } \\
\text { course after two } \\
\text { months }\end{array}$ & $\begin{array}{l}\text { Number of } \\
\text { participants who } \\
\text { finished the e- } \\
\text { course }\end{array}$ \\
\hline P0. AGH (PL) & 100 & 34 & 34 \\
\hline P1. CARNet (CR) & 38 & 22 & 20 \\
\hline P 2. RPiCViP (CZ), & 17 & 7 & 4 \\
\hline P 3. VMU (LT) & 42 & 20 & 18 \\
\hline P4: CPI (SL) & 30 & 27 & 9 \\
\hline P 5: Universidad de Murcia (ES) & 18 & 3 & 4 \\
\hline P6: CESIE (IT) & 35 & 15 & 12 \\
\hline P 7: HIST (NO) & 13 & 2 & 2 \\
\hline
\end{tabular}

Fig. 1. Number of participants in the pilot course.

They filled in the first three questionnaires after having completed three groups of Modules: 1-3 /4-6/ 7-10, and the fourth one - at the end of the course. The first three surveys were composed only of 'closed questions', since the quantitative feedbacks are extremely helpful in assessing the overall course contents. The final questionnaire featured also "open questions".

In the upcoming pages we would like to report the learners' responses on the assessments of VETeL e-course in the 8 partners' languages. The questions concerned the contents, the activities and the acquired competencies as well.

\section{LEARNER'S QUESTIONNAIRES}

\section{A. Learners' Questionnaire Module 1-3}

The first questionnaire was composed of 16 closed questions concerning the content, the activities and the learning objectives of Modules 1-3. 128 learners from the 8 partners' countries filled in this first questionnaire.

In the first question about the Moodle (Are you able to use Moodle to a degree which allows you to participate to the course?) 111 participants - out of 128 - stated that they are able to use Moodle very well, so as to participate in the course; while just a low number of participants (15) needs further clarification regarding Moodle and its use. For this reason it might be said that Moodle is a good and useful tool to implement eLearning, courses. So consequently it is a potential for using this tool in the teaching practice in VET institutions.

When we asked about their competencies to share information about themselves and other course participants, 
we found that 107 participants - out of 128 - acquired the competence to share information about themselves thanks to Module 1. Only 2 participants felt they had not acquired this competence. This means Module 1 contains enough activities to introduce oneself.

In the question "After Module 1 did you acquire the skill to plan your time in order to participate at the course?" the prevalence of positive answers (99) shows that activity 1.6 was useful for learners in order to learn how to manage their time for participating in the course.

About the opportunities to introduce themselves in Module 1 , we found one more time positive answers. Concretely 119 participants - out of 128 (91 very good+28 good)- evaluated positively the Module 1 of the course for introducing themselves.

Then, wen we asked "After Module 2 did you understand the concept of competence in VET?" most of responses (82\%) show that after having completed Module 2, participants felt they have understood the concept of competence in VET context. So it might be said the aim of the Module has been achieved. Also, most of participants could identify the key elements of a competence after having completed Module 2 (89\% of the answers are split between definitely yes and rather yes).

Some resources were implemented to help students to understand the concept of competence. One of them was a video about a taxi driver. The video was judged positively by a high percentage of respondents, in fact $89 \%$ has stated it helped them to understand the concept of competence.

Also, the activities from Module 2 in the students' opinion were helpfully to identify the competences. Only $10 \%$ of participants didn't identified their competencies after having completed Module 2. This means that the learning purpose of the Module has been achieved.

Then we asked if they understand which competences can be acquired by using ICT? 114 respondents - out of 128 stated they understood the competencies acquired by using ICT.

Another important aspect explained in the course was the link between competences and evidences including in a table of competences. Most of the participants affirmed (109 out to 128) to have understood the link between the competences and the evidences, thanks to the Module 2. This means the Competence table is an useful tool to reflect and identify/ map their acquired competence. In the same way, when we asked about the understanding of the link between reflection and learning, only $2 \%$ of the learners ( 3 responses out of 128 ) did not understand the link between reflection and learning, explained in Module 2, this means the Module is clear in explaining its content.

The topic in module 3 was about eLearning. In the question "after Module 3 are you able to identify different forms of eLearning?" $90 \%$ of participants stated a good understanding of the different forms of eLearning.

In relation with the usability of videoconference tool in eLearning in VET context, a high number of participants (106 -out of 128) had considered useful to use the videoconferencing tool and the other eLearning tools in their own vocational context.

About the learning outcomes, we found that the $89 \%$ of learners who participated these first 3 Modules declared to consider the learning outcomes of Modules 1-2-3 relevant for their work as teacher in a VET context, so we can affirm the satisfaction degree of these 3 Modules is positive. In addition, the learning objectives of these 3 Modules seem to be clear enough for most of the participants [89\% split between rank 1 (definitely yes) and 2 (rather yes)]. Moreover, $44 \%$ stated a good achievement of learning objectives and $49 \%$ a very good achievement as for these first 3 Modules, this means $93 \%$ of positive answers, so we would consider it as highly satisfactory outcome .

In general, the first 3 Modules stands at 1.70, far above the arithmetic average (2.5), this is a very good outcome and points clearly at the fact that the most of learners have had a positive assessment about the course contents and the learning objectives concerning these 3 Modules. Some exceptions:

- 8 Slovenian learners - out of $16(50 \%)$ - haven't acquired the competence to share information about itself after having completed Module 1;

- 8 Croatian learners - out of $13(62 \%)$ - state they haven't acquired the skill to plan their time in order to participate into the course after the activity 1.6 ;

- 8 Lithuanian learners - out of $16(50 \%)$-haven't understood the concept of competence in VET context after Module 2;

- a high percentage of Slovenian learners - 20 out of 24 $(83 \%)$ - felt they haven't reached the learning objectives of these 3 Modules.

\section{B. Learners' Questionnaire Module 4-6}

The second instrument for learners was the "Learner's Questionnaire Modules 4-6" This instrument was composed of 19 closed questions concerning the content, the activities and the learning objectives of Modules 4-6. 91 learners from 8 partners' countries have filled this second questionnaire. This first number shows that the numbers of participants from Module 1 to Module 6 decreased of $29 \%$.

The concept of e-tivity is crucial for the e-course, $93 \%$ of participants stated they learnt this concept after having completed the Module 4 as well as they learnt to design an e-tivity for VET context after having completed this Module.

The aim of this Module was to help the participants to create learning outcomes, $92 \%$ stated they have acquired the competence to design an e-tivity to reach a specific learning outcome.

The aim of Module 5 was understand the benefits of mobile technologies for the learning process.

$88 \%$ of learners stated to be able to profit from mobile technologies for the learning process in their VET context producing and sharing a short video clip, we found that the most of responses show participants learnt to produce and share a video clip thanks to the Module 5. Also, 78\% of learners learnt to produce and record an audio file in this module, $89 \%$ of learners learnt to write a scenario for video/audio production and $85 \%$ of participants stated they can design an e-tivity including a video/audio file.

The majority of participants (94\%) acquired the competence to analyze and compare good and bad instructional videos, $79 \%$ of learners learnt to involve students in the video/audio production and $81 \%$ of 
participants learnt to provide instruction for students on how to use or create a video/audio file as a learning resource. We can conclude that the learning objective of this Module has been achieved.

Module 6 was about Open Educational Resources (OER).

$90 \%$ of participants stated they learnt to search and select OER according to the learning objective after having complete this module.

The knowledge of the Creative Commons licenses is necessary in order to learn how to re-use the OER, 93\% (44\% definitely yes+ $49 \%$ rather yes) of learners stated to have acquired this competence and $93 \%$ of participants judged the video in Module 6 about Creative Commons License was useful to understand the system. Moreover the most of participants $(91 \%)$ stated they understood the difference between using copyrighted content and OER after having completed this Module.

Summing up, these others 3 Modules stands at 1,73, far above the arithmetic average (2.5), this is a good output and points clearly at the fact that the most of participants have had a positive evaluation about the contents and the aims of these 3 Modules. Even if the most of participants didn't rate the learning contents and aims of these Modules entirely positive, only 2 questions (n. 1 and 19) out of 19, have obtained the $51 \%$ of responses definitely yes, all the others have been assessed positive enough.

\section{Learner's Questionnaire Modules 7-10}

It was the third learner's questionnaire and it composed of 13 closed questions concerning the content, the activities and the learning objectives of Modules 7-10.

79 learners from 8 partners' countries have filled this second questionnaire. This first number shows that the numbers of participants from Module 1 to Module 6 decreased of $40 \%$.

Module 7 was about motivation in eLearning.

$91 \%$ of participants stated they can outline the factors that influence the level of motivation among the participants of an eLearning course. This means that the learning objective of this Module has been achieved by most of learners.

When we asked "after Module 7 are you able to use any methods to stimulate the activity among participants? The most of responses $94 \%$ shows that participants thanks to this Module have acquired the competence to stimulate the activity among participants.

The topic in module 8 was the group work. $87 \%$ of participants stated they learnt to design an e-tivity for group work in the VET system and $73 \%$ of learners have understood the importance of cooperation in an eLearning environment in order to motivate participants. When we asked if they found the eLearning tools for group work listed in Module 8 useful for your work as a VET teacher, the most of responses (89\%) shows that participants found the eLearning tools for group work listed useful for their work as VET teachers. Moreover, most of participants (84\%) acquired the competence to organize a videoconference for a group work.

In module 9, about online discussions, 94\% of learners declared that after having completed this module they acquired the competence to open and moderate an online discussion, this means that the main learning objective of this
Module was achieved. Also, 93\% of learners declared that they acquired the competence of participating in an online discussion within a forum discussion and $92 \%$ of participants have acquired the competence to identify and solve a problem within a Forum discussion.

The last module was about the facilitator's role. $36 \%$ of participants felt that after the participation at the e-course they completely acquired the skills to organize and an eLearning course, $51 \%$ felt positive enough. In spite of this data, most of participants (93\%) declared they understood the facilitator's role in an online course and $96 \%$ stated they understood the facilitator's competences needed to manage an e-course. Last question in this questionnaire was "could you identify your skills as an eLearning course facilitator? 93\% stated they can identify their skills as a facilitator after having participated to the e-course, this means they felt they improved their facilitators skills.

These last 4 Modules stands at 1.55, far above the arithmetic average (2.5). This group of Modules have achieved an higher score than others. This means that participants have perceived these modules better. Learners did a positive assessment about the contents and the learning objectives of these last Modules.

\section{Final Learners' Questionnaire}

To conclude whit the learner's opinion about the course they did a final questionnaire.

The final learners' questionnaire was composed of 14 questions, 12 closed questions and 2 open questions. The closed questions concerned the overall evaluation of the e-course, the evaluated topics were: the usefulness of the participation in the course, the satisfied expectations, the improvement of pedagogical skills as VET teacher and the improvement of technical skills as a designer of an e-course in a VET context, the learning outcomes, the interaction between participants, the facilitator's role and finally, the aim of competence table as a self-reflection of acquired competences. Two open questions were included in the questionnaire in order to gather additional comments, suggestions and recommendations for a further improvement of the e-course.

78 learners from 8 partners' countries have filled in this final questionnaire. This means that $61 \%$ of participants who started the course finished all ten Modules.

Some important data from this questionnaire was $66 \%$ of learners stated completely positive their participation in the course, and $26 \%$ good positive, this means $94 \%$ of participants are very satisfied. Also, 61 learners- out of 78responded that the course has satisfied their initial expectations, only 17 stated they didn't satisfied their expectations after attended the e-course.

An important question was about their pedagogical skills. "after the course did you improve your pedagogical skills as teacher for vocational subjects?" This is a crucial question since one of the main project's aim for target group (VET teachers/trainers) is to improve their pedagogical skills. Most of participants $(89 \%)$ declared improved their pedagogical competences; this means the course achieved one of its main objectives.

Another important project's aim for the target group (VET 
teachers/trainers) is to improve technical skills. Most of participants $(83 \%)$ declared improved their technical competences; this means the course has achieved another important objective.

In order to pass the course and receive the certificate, participants are required to continuously (after each module) record the table of competences, which is a tool to reflect on the development of each competence throughout the course. $83 \%$ declared the table was useful to as a self-assessment tool.

In relation with the timetable, 53\% (42 learners- out of 37) stated they could follow the whole course at the time it was planned. This means the course needed more time to be completed. However the time management should be adapted in depending of the target group knowledge.

Then we asked students about what would they like change in the organization of the course (this was the first of two open questions included in this final questionnaire). Participants declared what they would change in the organization of the course providing many suggestions to improve the course. The most relevant were:

- Adding other videoconferences, since they can improve engagement, participation and communication among participants.

- Sometimes it is requested more time to finish the course (It depends on the target group knowledge).

- Facilitator should be very clear in the assignments' explanations

Other open question of the questionnaire was refers to the content of the whole course (what would they like change about the content?). Participants suggest to:

- Separating some modules in two or more.

- Decreasing the content of same paragraphs.

- Adding more concrete examples.

- Adding more practical exercises.

About the structure of the course, we found a positive feedback from most of participants $(89 \%)$. Also, almost all participants $97 \%$ declared they considered relevant the learning outcomes of the whole course to improve their competences as facilitators of an e-course.

The interaction between participants for activities implementation is fundamental because learners can benefit from the activity of other course participants; learn from them as well as with them. $83 \%$ of participants declared they were satisfied of the interaction among participants. This interaction happens through exchanging views on the discussion forum, commenting on each other's posts, citing others and posting links. $91 \%$ of participants stated the tools for interaction were useful to learn.

The facilitator's role was very important in the development of this course. $88 \%$ of participants declared the facilitators provided them enough support, this means they acquired an important role to guide participants during the e-course.

We found very interesting that $88 \%$ of participants will recommend the course to other teachers. This means a good satisfaction degree by most of participants.

The responses to this final questionnaire confirm the overall positive assessment of the course for the most of participants. The points evaluated have received very high scores by all the transnational participants, in particular:
- Usefulness of the participation in the course (92\%).

- Fulfilled expectations (78\%).

- Improvement of pedagogical skills as VET teachers (89\%).

- Improvement of technical skills as a designer of a e-course in a VET context $(83 \%)$.

- Interaction between participants $(83 \%)$.

- Facilitator's role (88\%).

The questionnaire included two open questions: the first one explored the structure of the course and the second one explored the course contents. Participants have evaluated positively both the course structure and its contents; they also provided many suggestions for improving the course.

\section{E. Questions for people who dropped-out the course}

To conclude with the learners' opinion and complete the piloting evaluation was very important to have the opinion of people who dropped-out the course in order to understand if their decision could be linked to the course contents or structure. 16 learners from 5 partner countries have answered the following questions:

First question was "Why did you drop-out?" Most of responses show that participants decided to leave the course for personal reasons and in particular due to lack of time related to their responsibilities and work overload, only one person out of 16 stated he dropped-out the course for lack of interest in elearning, besides 2 people abandoned the course due to a slow Internet connection or no Internet access at home.

Second question was "Was the course challenging enough? The responses to this question were all positive, almost all of the participants felt the course was challenging enough. Only 2 people stated they couldn't answer because the dropped-out at the beginning of the e-course.

Then we asked, "What did you find boring in the course?" Participants who abandoned the course, also judged it positively ( $88 \%$ of responses). Only 1 person considered the assignments boring, while another one suggested to add images to the texts.

In the question "What did you find interesting on it?" Learners found many interesting aspects: the structure, contents, processes, good leadership and communication rate within the group, support and motivation among participants and facilitator, innovation and interactivity.

\section{CONCLUSIONS}

As foreseen in the project proposal, the partners from Poland, Croatia, Czech Republic, Norway, Slovenia, Lithuania, Spain and Italy implemented the VETel e-course meeting the planned objectives and reaching the expected results. The participants were recruited directly from the partner organizations or with the support of some associated partner in their own countries.

The overall evaluation, as stated by participants and facilitators involved in the implementation of the VETeL e-course shows that the level of attendance and commitment to the proposed activities was very high.

The e-course was implemented, all the 10 Modules were tested. In total 128 participants attended the VETeL e-course while "only" 64 ( 8 per country) have been foreseen by 
eVET2EDU project proposal. This increased number of participants didn't have influence on the overall budget while in positive, it allowed a better management in terms of group building and was also a motivation aspect for the VET teachers to finish the courses.

The participants ensured that the content of the e-course was relevant as a teacher in to a VET context and that they were personally interested in the content.

The lowest overall evaluation score of all was give in connection with the scope and duration of the training as a whole; many participants felt that the time available was simply too short for all of the interesting aspects and features to be dealt with properly. Therefore, future VETeL e-course may consider allowing more time for their implementation.

All the evaluated points have been scored with a high score by all participants in different countries. However, it should always be considered whether or not such materials need to be adapted to local and national circumstances and demands in order to increase their effectiveness.

The participants evaluated the VETeL e-course being aware of having learned and acquired new competences appreciating the innovative aspects in terms of contents, approach, methodology and sector.

The constructive criticisms expressed by participants and facilitators will be highly useful in order to improve quality and effectiveness of future VETeL e-course. Project partnership explored the possibilities to integrate the course into curriculum and maintain the course to open repositories, course databases and webpages after the eVET2EDU project has ended.

To conclude, the eVET2EDU Partnership is very satisfied by the reached results in terms of impact at all levels. All activities were implemented successfully in terms of fulfilling all of the quantitative requirements in connection with the proposal as well as in terms of obtaining a high degree of positive feedback and evaluation in connection with the quality aspects of the open eLearning course.

\section{ACKNOWLEDGMENT}

Authors would like to thanks to EVET2- Edu partners, for doing possible the piloting of the project.

\section{REFERENCES}

[1] Project E-VET2EDU. Supporting vocational teachers and trainers in elearning. [Online]. Available: http://evet2edu.eu/index.html

[2] European Ministers of Vocational Education and Training, and the European Commission. (November 2002). Enhanced European Cooperation in Vocational Education and Training. [Online]. Available: http://ec.europa.eu/education/pdf/doc125_en.pdf

[3] European Ministers for Vocational Education and Training. (December 2010). Review the Strategic Approach and Priorities of the Copenhagen Process for 2011-2020. [Online]. Available: http://ec.europa.eu/education/lifelong-learning-policy/doc/vocational/ bruges_en.pdf

[4] R. Andrews and C. Haythornthwaite, The Sage Handbook of ELearning Research, London: Sage publications, 2006.

[5] UNESCO, Open and Distance Learning. Considerations on Trends, Policies and Strategies. Division of Higher Education, Trilce: Uruguay, 2002.

[6] European Council of Lisbon, "VET elearning needs' data analysis report," Communication of 8 December 1999 on a Commission Initiative for the Special, March 2000.

[7] A. Head, M. V. Hoeck, and D. Garson, Lifelong Learning in the Digital Age: A Content Analysis of Recent Research on Participation, First Monday, 2015.
[8] L. Johnson, S. Adams, S. Becker, V. Estrada, A. Freeman, P. Kampylis, R. Vuorikari, and Y. Punie, Horizon Report Europe: 2014 Schools Edition, Luxembourg: Publications Office of the European Union, \& Austin, Texas: The New Media Consortium, 2014.

[9] S. Leone, "F2F learning vs. elearning: The lifelong learner's point of view," in Proc. INTED 2010, Valencia, Spain, 2010.

[10] S. Leone, Characterisation of a Personal Learning Environment as a Lifelong Learning Tool, New York: Springer Briefs in Education, 2013.

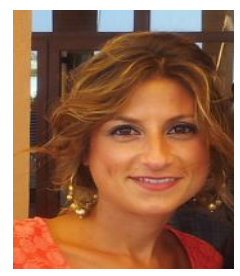

Isabel Gutiérrez was born in Murcia, Spain, in 1984 She got the degree in pedagogy at the University of Murcia (Spain) in 2007, and the master in e-learning: Educational technology and knowledge management at the University of Balearic Islands (Spain) in 2008, and the $\mathrm{PhD}$ in educational technology at the University Rovira I Virgili (Tarragona, Spain) in 2011. Her field of study is educational technology.

She is assistant professor in educational technology in the Department of Didactics and School Organization at the University of Murcia (Spain). She is also one member of the Group of Research in Educational Technology (GITE) at the University of Murcia. She teaches in degrees related to education. She is lecturing at the Faculty of Education, in the degrees of social education, future primary school teachers, and also in the masters of technology enhanced learning. She is author of the book Digital Educative Resources (Madrid, Spain: Síntesis, 2010). She is author of some important book chapter like Social Networks and other spaces online to connect people (Sevilla, Spain: MAD, 2010), Analysis Model of the ICT competence of the University Teachers (Alcoy, Spain: Marfil, 2011). She has participated in national and international research projects centered on the use, integration and evaluation of information and communication technologies in education; social networks, ICT in the hospital classrooms, personal learning environments, etc. Also, she has spent some periods of working in research visiting at the Massachusetts Institute of Technology (Massachusetts, USA), Trinity College (Dublin, Ireland), National University of Ireland (Galway, Ireland).

Dr. Gutiérrez is honor degree in Pedagogy and Extraordinary Award in pedagogy in Spain. Also, she got Extraordinary Doctorate Award. Dr. Gutiérrez is one member of EDUTEC (International and Professional Association to promote Educational Technology and New Technologies in Education.).

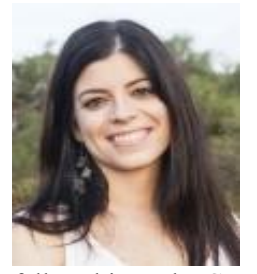

M. Mar Sánchez was born in Cartagena, on October 18, in 1982. She ended in 2006 the degree in pedagogy, at the Faculty of Education in Murcia, Spain. In 2007 she got a fellowship in the National Institute of Educational Technology at the Ministry of Education in Madrid. Spain. From 2008 to 2010 she worked as PhD student at the University of Murcia. She also had collaborated in 2008 with a research fellowship at the Centre for Applied Research in Educational Technology at the University of Cambridge (UK) and in 2013 in the Centre for Innovation in Technologies and Education (CITE) at the University of Southampton (UK). Currently, she is senior lecturer at the University of Murcia (Spain), in the Department of Didactics and School Organization. She teaches in degrees related to education, like pedagogy, Social education, elementary teachers and kindergarden teachers. And she is also in the master of technology enhanced learning.

She had published several book, chapters papers related with her research experience in education and technology. Some examples are "Web Semántica: aplicaciones prácticas para la educación" (Madrid: Dykinson, 2012), the article "Beyond objective testing and peer assesstment: alternative ways of assessment in MOOCs" in RUSC, Vol 12. (2015), or at least "Challengues in the creation, development and implementation of MOOCs: Web Science at the University of Southampton", in Comunicar, 44 (2015). Her research experience and current interest is related with Semantic Web, MOOCs, social networks and, in general, the use of technology in educational environments.

Dr. Sánchez is one member of EDUTEC, association related with education of technology and part of the Group of Research in Educational Technology (GITE). 


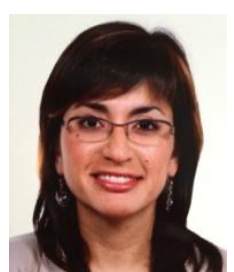

Linda Castañeda is assistant professor in educational technology in the Department of Didactics and School Organization at the University of Murcia (Spain). She is also one member of GITE (Group of Research in Educational Technology) .She is educationalist from the University of Murcia and $\mathrm{PhD}$ in educational technology by the University of Balearic Islands (Extraordinary Doctorate Award and European Mention).

She has spent some periods of working in research visiting at the Knowledge Media Institute at the Open University of UK, The Group of Research in e-learning of the University of Oxford, and The Centre for Education and New Technologies (CENT) from the Universitat Jaume I of Castellon (Spain). With her background in Educational Technology, she has participated in national and international research projects centred on the use, integration and evaluation of Information and Communication Technologies in Education, e-learning, and the impact of those on the Social, Curricular and Organizational change. Currently, her research is around Web 2.0 in education and training, Personal Learning Environments and Emergent Technologies and Pedagogies.

Dr. Castañeda has participated in a wide variety of international events as speaker and I has published some books (her last book about PLEs is completely available on the Internet http://www.um.es/ple/libro) and papers in specialized journals and conferences. She teaches in degrees related to Education, She is lecturing at the Faculty of Education, in the degrees of
Pedagogy, Social Education, Future primary school teachers, and also in the Masters of Technology Enhanced Learning.

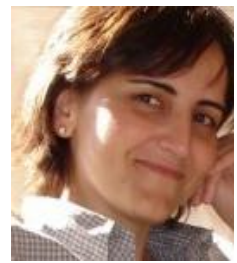

Paz Prendes was born in Cartagena, Spain, in 1967.

She studied the PhD in sciences of education (1994) with Extraordinary Award and university expert in educational technology. She is professor of the Department of Didactics and School Organization and also the head of the Research Group about Educational Technology at the University of Murcia (Spain). She is the coordinator of both the "Master in Educational Technology: E-Learning \& Knowledge Management" and also the "PhD Program in Educational Techlogy" at the University of Murcia.

She has been working at the University of Murcia since 1990 when she finished her Degree in Sciences of Education with a national award. She has published books as "Nuevas Tecnologías y Educación" (Madrid: Pearson, 2004) or "Las TIC en las Aulas Hospitalarias" (Alicante: Marfil, 2012) and articles about e-learning, digital competence, instructional design, semantic web, collaborative learning, MOOC and uses of technologies in education in general.

Prof. Prendes is also secretary of EDUTEC, International and Professiona Association to promote Educational Technology and New Technologies in Education. Reviewer of Pixel-Bit, NAER or Educación XXI among others 